\title{
Stability Indices for Horticultural Crops
}

\author{
Marvin Pritts \\ Department of Pomology, Cornell University, Ithaca, NY 14853
}

James Luby

Department of Horticultural Science and Landscape Architecture, University of Minnesota, St. Paul, MN 55108

The mean yield of a crop genotype measured over several years or locations has often been used as a measure of performance or adaptability. While this characteristic provides one indicator of performance, it does not provide information on the underlying basis of the performance. For example, a moderate mean value for a particular response would occur if several test locations reported moderate values, or if a few sites reported high values while a similar number reported low values. An assessment of adaptability or yield stability would be quite different in these two cases.

There are many situations where stability may be as important as mean performance. For example, consistent production may be more desirable than high yields when irregular yields contribute to problems with marketing and pricing policy. An index that reflects phenotypic stability would be beneficial for evaluating crop response.

Several procedures have been developed to assess the stability of performance over a range of conditions. For the most part, these procedures have been used by breeders to assess the stability of yield for various genotypes. Stability indices have helped improve recommendations to growers, and have allowed researchers to identify well-buffered genotypes for use in breeding programs. However, the concept and meaurement of stability need not be confined to plant breeders or to yield-ecologists, biochemists, physiologists. and developmental biologists also have hypotheses that concern the basis for stability in biological systems. Horticulturists have made use of these techniques (Table 1), but to a limited extent.

The objective of this study is to provide an introduction to the measurement and application of stability analysis in horticulture. We will restrict our discussion to yield, although we acknowledge that many other traits can be subjected to this type of analysis.

\section{STABILITY INDICES \\ Concepts of stability \\ Several different concepts of stability ex-}

Received for publication 9 May 1989. We acknowledge the assistmce of David Bedford, David Wildung, Kay Sargent, Wcs Gray, Steve Poppc, and Melvin Wiens with data collection. Marcia Eamcs-Shcavly assisted with data analysis, and James Hancock, J. Scott Cameron, and Chuhe Chen provided helpful reviews. The cost of publishing this paper was defrayed in part by the payment of page charges. Under postal regulations, this paper therefore must be hereby marked advertisement solely to indicate this fact. ist, and different indices reflect these various concepts. In one sense, stability can be thought of as a homeostatic state, defined as low variation in yield when measured over various locations or years. Numerous authors in the early 1900 s reported deviations from the genotypic mean, and used standard statistical techniques to compare the variance of genotypes across environments. The square root of these variances can be divided by the genotypic mean and multiplied by 100 to obtain a coefficient of variation for a particular trait; this procedure standardizes the deviations relative to the magnitude of the mean value.

Coefficients of variation are useful for assessing traits that should not vary significantly in response to the environment (e.g., quality, disease resistance), but, with more phenotypically plastic traits, such as yieid, a different measure of stability is required.

For many quantitative traits, it may not be desirable for a genotype to have low variability. For example, a desirable cultivar should respond positively to improved environmental conditions provided by a grower, rather than exhibit a constant performance. If many environments are ranked according to their yield potential, then one would expect the performance of a genotype to change in a predictable way across this range of environments. A more dynamic concept of stability has been defined as the degree of response of a genotype to these changing environments. The static concept is only concerned with the magnitude of change, while the dynamic concept is concerned with the rate of change.

Suppose one could assign numbers to many different environments that would reflect their quality or yield potential. If the performance of an individual genotype in each of those environments was related to the quality of those same environments, then one would expect to observe a linear relationship, i.e., as the yield potential of a site increases, the performance of the genotype would also increase. This dynamic concept of stability can be quantified using regression techniques.

The rate of change in a genotype's performance relative to the site potential is a predictable quantify, and is an inherent char-

Table 1. Methods or indices used to assess stability in horticultural crops.

\begin{tabular}{|c|c|c|c|}
\hline Crop & Variables & Description of indices & Reference \\
\hline Bean & Yield & Multivariate cluster analysis & Ghaderi et al. (1982) \\
\hline Blueberry & Yield & $\begin{array}{l}\text { Regression coefficients } \\
\text { Deviations from regression }\end{array}$ & Siefker and Hancock (1986) \\
\hline Carrots & $\begin{array}{l}\text { Yield } \\
\text { Split roots (\%) } \\
\text { Purple-topped roots (\%) }\end{array}$ & $\begin{array}{l}\text { Analysis of variance } \\
\text { Regression coefficients }\end{array}$ & Dowker et al. (1978) \\
\hline Collards & Yield & $\begin{array}{l}\text { Regression coefficients } \\
\text { Coefficients of determination }\end{array}$ & Olson and Stoffella (1989) \\
\hline Muskmelon & $\begin{array}{l}\text { Yield components } \\
\text { Soluble solids }\end{array}$ & $\begin{array}{l}\text { Coefficients of variation } \\
\text { Regression coefficients }\end{array}$ & $\mathrm{Ng}$ et al. (1980) \\
\hline Okra & $\begin{array}{l}\text { Yield components } \\
\text { Days to flowering }\end{array}$ & $\begin{array}{l}\text { Regression coefficients } \\
\text { Deviations from regression } \\
\text { Coefficients of variation }\end{array}$ & Ariyo (1987) \\
\hline Onions & $\begin{array}{l}\text { Yield } \\
\text { Winter kill } \\
\text { Bolting } \\
\text { Maturity }\end{array}$ & $\begin{array}{l}\text { Analysis of variance } \\
\text { Regression coefficients }\end{array}$ & Fennell and Salter (1977) \\
\hline Peas & $\begin{array}{l}\text { Yield components } \\
\text { Days to flower } \\
\text { Growth habit }\end{array}$ & $\begin{array}{l}\text { Analysis of variance } \\
\text { Regression coefficients }\end{array}$ & Snoad and Arthur (1976) \\
\hline Strawberry & Yield & Regression coefficients & Hancock (1985) \\
\hline Strawberry & Yield & Regression coefficients & Williams (1975) \\
\hline Sweet potato & $\begin{array}{l}\text { Yield } \\
\text { Leaf scab incidence }\end{array}$ & $\begin{array}{l}\text { Regression coefficients } \\
\text { Coefficients of determination }\end{array}$ & Kanua and Floyd (1988) \\
\hline Tomato & Yield & $\begin{array}{l}\text { Regression coefficients } \\
\text { Deviations from regression } \\
\text { Coefficients of determination }\end{array}$ & Stoffella et al. (1984) \\
\hline Tomato & $\begin{array}{l}\text { Yicld } \\
\text { Soluble solids } \\
\text { Citric acid content }\end{array}$ & Regression coefficients & Berry et al. (1988) \\
\hline Tomato & Yield & $\begin{array}{l}\text { Regression coefficients } \\
\text { Deviations from regression }\end{array}$ & Poysa et al. (1986) \\
\hline
\end{tabular}


acteristic of the genotype. Some genotypes can be expected to be less responsive than others, and these would be more stable. Theoretically, this trait would be heritable, and could be used to develop high-yielding, stable cultivars. However, an unpredictable component of the response also exists - this is the variation that cannot be explained by a linear model, and is that portion that exists after the genotypic response is accounted for. Using still another concept, a stable genotype could be defined as one exhibiting little deviation from the predicted linear response to changing environments. Many different indices have been proposed to quantify these various concepts of stability.

Lin et al. (1986) examined nine stability indices and concluded that they fell naturally into three groups. One group measured absolute variation across environments and usually involved an analysis of variance approach. A second group assessed cultivar performance relative to a measure of environmental performance and involved a regression approach. A third group examined deviations from regression as a measure of stability. Francis and Kannenberg (1978), Brennan and Byth (1979), Gray (1982), and Ntare and Aken'Ova (1985) evaluated the usefulness of several different stability indices with a single set of data.

\section{Analysis of variarice approach}

Salmon (19.51), Homer and Frey (1957), and Plaisted and Peterson (1959) used an analysis of variance (ANOVA) approach to compare the consistency of yield across locations. Cultivar yield data across locations were analyzed in pairs, using all pairwise combinations of cultivars in separate analyses of variance. In each analysis, the cultivar $\times$ location component of variance was obtained. The average of these components for all combinations having a cultivar in common was a measure of cultivar stability. This technique provides the relative contribution of each cultivar to the overall cultivar $\times$ location interaction.

Wricke (1962) used a more simple computational procedure, termed ecovalence, to measure the contribution of a genotype to the genotype $\times$ environment interaction. This statistic squares and sums deviations from the genotypic contribution to yield across all environments. Genotypes contributing little to the interaction component are considered stable.

Shukla (1972) also has proposed an estimate of the variance for individual genotypes, termed "stability variance". This measure of stability incorporates the concept of ecovalence, but is more computationally difficult.

These ANOVA techniques separate various environmental and genetic components of stability, but provide only relative measures of stability. The magnitude of these stability indices depends on the scaling of the measured variable and is proportional to the differences between environments. Direct comparisons or indices among different studies are often not meaningful, although nonparametric ranking procedures are useful.

\section{Regression approach}

Findlay and Wilkinson (1963) reasoned that phenotypic stability could also be quantified with a regression approach, using an environmental index as the independent variable and yield as the dependent variable. Since quantification of the exact environmental traits that influence yield (rainfall, temperature, etc.) is often not possible, the average performance of all cultivars in a particular study could be used as a measure of environmental quality. The linear regression coefficient of individual cultivar performance on overall mean cultivar performance (B) could then be used as a measure of stability.

This index removes much of the relativity inherent in the ANOVA approach because the genotypic mean performer would have an index of 1.0. Cultivars with regression coefficients $<1.0$ can be considered stable, while those with coefficients $>1.0$ are unstable (Fig. 1). A stable cultivar, therefore, is one that responds less-than-average to changes in environment.

Stability estimates derived from regression procedures are easily compared among studies. Scaling problems are reduced because the average genotype always has a stability estimate of 1.0. This particular method of estimating stability also has a history of use among agronomists, who have used this approach to identify high-yielding, stable genotypes (Heinrich et al., 1983; Saeed and Francis, 1983; Tan et al., 1979; Breese, 1969; Carver et al., 1987).

Eberhart and Russell (1966) argued that high yield and small regression coefficients were only two of the three criteria needed for assessing cultivar performance. The third was deviation about regression (the unexplained deviations from regression on the environmental index). They argued that the regression coefficient measures only the predictable part of stability; the unpredictable part should also be quantified and considered in stability analysis. Several studies have

\section{Cultivar Mean}

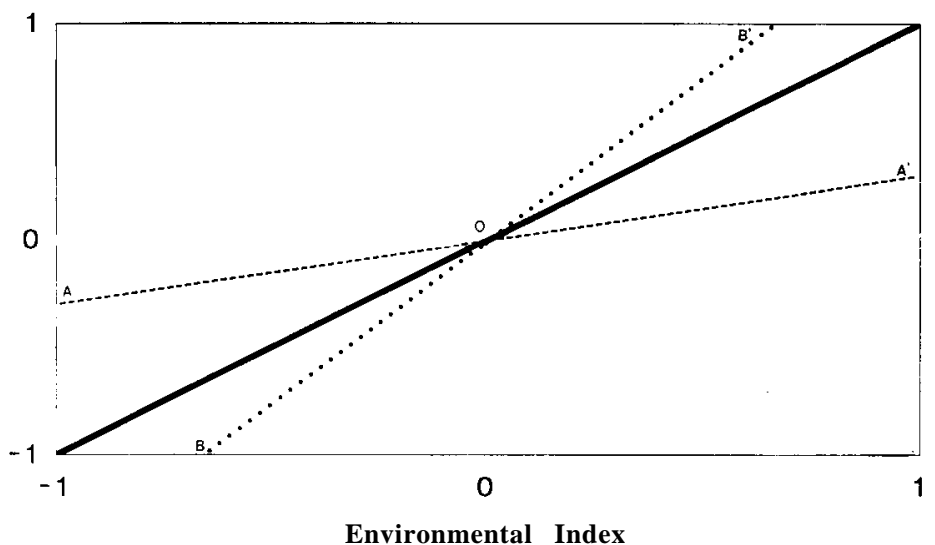

Fig. 1. Cultivar means of hypothetical genotypes regressed against a corresponding environmental index. The solid line represents the average genotype with a stability index of $\beta=1.0$. Using the same method, line BOB' represents a genotype with below-average stability, and lineAOA' exhibits above-average stability. Line segments AOB' represent a more ideal genotype, as described by Verma et al. (1978). considered this criterion when assessing cultivar stability (Table 1).

Pinthus (1973) argued for the use of the coefficient of determination $\left(\mathrm{R}^{2}\right)$ instead of deviation mean squares to assess the unpredictable part of variability. Both are related statistically, but the coefficient of determination, similar to the regression coefficient, is independent of the units of measurement.

Hanson (1970) proposed a stability index based on a regression approach, but which included the portion of environmental variance that could be reduced by imposing selection pressure. The index measures stability relative to the smallest regression coefficient in a group of genotypes, and incorporates the concept of deviation mean squares.

Verma et al. (1978) argued that such conventional regression approaches are deficient because of the assumption that a predictable linear response exists along an environmental gradient. First, biological relationships are often not linear, and second, they suggested that a desirable genotype should be relatively are unfavorable, but respond strongly to favorable environments. Their approach is to create an environmental index with a mean of zero, and perform a separate regression analysis for negative values of the environmental index, and another for positive values. One would then seek a genotype with a small regression coefficient in poor environments, but a large regression coefficient in good environments (Fig. 1). This procedure eliminates many of the problems associated with nonlinear genotype-environment interaction components, yet allows the use of conventional linear regression techniques.

\section{COMPARISON OF STABILITY INDICES}

\section{Strawberry data set}

Methodology. By using a data set comprised of strawberry yields over several different years and locations, we were able to estimate cultivar stability using five methods, each of which is sensitive to different insensitive to environment when conditions 
types of stability. We then were able to compare these different methods, explore their limitations, and show how stability estimates are affected by assumptions.

'Veestar', 'Honeoye', 'Crimson King', 'Redcoat', 'Kent', and 'Bounty' strawberries were fruited at four locations for 6 consecutive years (1983-1988). 'Stoplight', 'Badgerbelle', 'Canoga', and 'Sparkle' were fruited at these same four locations for 4 consecutive years (1983-1986). Locations were Excelsior, Morris, Staples, and Grand Rapids, Minn. In Grand Rapids, duplicate plantings were both mulched and unmulched, providing a total of five environments. Each cultivar was replicated four times at each location in a completely randomized design.

Plants were set at a $0.5 \times 1.2-\mathrm{m}$ spacing and grown in 0.4-m-wide matted rows in 3$\mathrm{m}$ plots. New beds were set every other year so that fruit was always harvested from young beds. Flowers were removed in the first year, and the planting received standard cultural care as described by Luby et al. (1984). Plants were harvested regularly and cumulative yield was determined for each replication at each location in each year.

Cultivar stabilities for the first set of six cultivars were estimated by the coefficients of variation, and methods of Homer, and Frey (1957), Findlay and Wilkinson (1963), Pinthus (1973), and Verma et al. (1978). All location-year combinations were treated as individual environments. With the exception of the Homer and Frey (1957) method, the same ones were used to assess stability when all 10 cultivars were included in the analyses. In addition, the method of Findlay and Wilkinson (1963) was used to assess the stability of a cultivar across locations only, and again for years only.

To compare stability estimates, it was necessary to have a single number represent the performance of each cultivar using each of the five methods. For convenience, the square root of the variance estimate of Horner and Frey (1957) and Plaisted and Peterson (1959) was used (abbreviated VAR); a lower number indicates increasing stability. An index representing Verma et al. (1978) was developed (abbreviated IIB) by subtracting the absolute value of the regression coefficient in poor environments from the regression coefficient in good environments. This estimate will increase when the response in good environments is above average, and change little when performance in poor environments is stable. Coefficients of variation, regression coefficients on the environmental index, and coefficients of determination were not modified (abbreviated $\mathrm{CV}, B$, and. $R^{2}$, respectively).

Results and. discussion. Analysis of variance of the entire data set indicated that cultivar, locations, years, and all the interactions were significant at $P<0.001$ (Table 2), and that significant genotype $\times$ environment interaction existed in the data. If no interaction exists in a data set, it makes little sense to conduct a stability analysis.

The cv was the only stability index as- sociated with yield (Tables 3 and 4). This negative association was expected because the denominator of $\mathrm{cv}$ is mean yield. Even if the deviations from the environmental mean were not standardized, a correlation with yield might still exist because higher-yielding genotypes also tend to have higher deviations.

Stability indices were not consistent in their evaluation of cultivar performance. The cultivar ranking using the $\mathrm{cv}$ was dissimilar to the others (Table 3 ), but the regression coefficients of determination $\left(R^{2}\right)$ were significantly correlated $(r=0.72, \mathrm{P}<0.02)$. Some dependency is to be expected because of the underlying statistical relationship between the

two parameters (Hardwick and Wood, 1972).

The indices derived from the linear regression approach (13) were correlated with those from the two regression model (IIß) of Verma et al. (1978); however, the relationship was negative. Not unexpectedly, those genotypes exhibiting stability across the entire range of environments. were not those that showed a positive response in good environments.

Some indices provided completely different assessments of genotypic stability. For example, according to the analysis of variance (VAR) and two regression (IIß) method, 'Honeoye' ranks near the top, while 'Redcoat' is at the bottom (Table 3). However, the single regression methods $\left(B\right.$ and $\left.R^{2}\right)$ as-

Table 2. Results of analysis of variance for genotype, location, year, and interaction effects for a strawberry data set.

\begin{tabular}{lrrrr}
\hline \hline Source & df & Mean squares & F & \multicolumn{1}{c}{$P$} \\
\hline Cultivar & 9 & 391 & 48.0 & 0.0001 \\
Location & 4 & 267 & 32.7 & 0.0001 \\
Cultivar $\times$ location & 36 & 36 & 4.4 & 0.0001 \\
Year & 5 & 496 & 60.8 & 0.0001 \\
Cultivar x year & 38 & 36 & 4.4 & 0.0001 \\
Location x year & 15 & 132 & 16.1 & 0.0001 \\
Cultivar x location $\times$ year & 93 & 19 & 2.3 & 0.0001 \\
Error & 525 & 8 & & \\
\hline
\end{tabular}

Table 3. Yields and stability indices of strawberry cultivars determined by various methods and using two sizes of data sets.

\begin{tabular}{|c|c|c|c|c|c|}
\hline Cultivar & $\mathrm{CV}^{2}$ & VAR $^{y}$ & $\beta^{\mathbf{x}}$ & $R^{2 \mathrm{w}}$ & $\operatorname{II} \beta^{v}$ \\
\hline \multicolumn{6}{|c|}{ Small data set } \\
\hline Redcoat & 38.2 & 2,700 & 0.799 & 0.464 & -1.449 \\
\hline Crimson King & 47.5 & 1,740 & 0.878 & 0.698 & -0.336 \\
\hline Bounty & 49.0 & 2,007 & 0.958 & 0.714 & 0.641 \\
\hline Kent & 39.1 & 2,418 & 1.031 & 0.626 & 0.037 \\
\hline Veestar & 55.7 & 2,101 & 1.106 & 0.705 & 0.287 \\
\hline Honeoye & 47.7 & 1,977 & 1.113 & 0.681 & 0.682 \\
\hline \multicolumn{6}{|c|}{$\begin{array}{l}\text { Large data set } \\
\text { Yield }^{w}\end{array}$} \\
\hline Sparkle & 41.3 & 8,292 & 0.652 & 0.199 & -0.893 \\
\hline Kent & 39.1 & 13,437 & 0.677 & 0.403 & 0.954 \\
\hline Redcoat & 38.2 & 11,279 & 0.720 & 0.436 & -1.741 \\
\hline Crimson King & 47.5 & 8,395 & 0.770 & 0.611 & -0.694 \\
\hline Canoga & 62.4 & 5,722 & 0.861 & 0.535 & 0.438 \\
\hline Bounty & 49.0 & 8,982 & 0.940 & 0.784 & 0.386 \\
\hline Veestar & 55.7 & 8,482 & 0.991 & 0.645 & 0.343 \\
\hline Honeoye & 47.7 & 11,229 & 1.034 & 0.676 & 0.366 \\
\hline Badgerbelle & $57: 3$ & 6,423 & 1.043 & 0.691 & 0.490 \\
\hline Stoplight & 52.7 & 8,835 & 1.327 & 0.808 & 1.981 \\
\hline
\end{tabular}

${ }^{z}$ Coefficient of variation across environments.

${ }^{y}$ Analysis of variance estimate of stability.

× Regression coefficient of cultivar mean on environmental index.

"Coefficient of determination for cultivar mean regressed on environmental index.

'Double regression method as described by Verma et al. (1978).

uYield measured in $\mathrm{g} / 3 \mathrm{~m}$ of row.

Table 4. Correlation coefficients between stability estimates.

\begin{tabular}{lcccrrr}
\hline & $\mathrm{CV}^{\mathrm{z}}$ & VAR & $\beta^{\mathrm{x}}$ & \multicolumn{1}{c}{$R^{2 \mathrm{w}}$} & \multicolumn{1}{c}{$\mathrm{II} \beta^{\mathrm{v}}$} & Yield $^{\mathrm{u}}$ \\
\hline CV & $\cdots$ & $-0.70^{\mathrm{t}}$ & 0.44 & 0.56 & 0.48 & -0.80 \\
VAR & & $\cdots$ & -0.52 & -0.74 & -0.33 & 0.65 \\
$\beta$ & & $\cdots$ & 0.72 & 0.73 & -0.19 \\
$R^{2}$ & & & $-\cdots$ & 0.58 & -0.22 \\
IIB & & & & -- & -0.06 \\
\hline
\end{tabular}

${ }^{x}$ Coefficient of variation across environments

${ }^{y}$ Analysis of variance estimate of stability.

*Regression coefficient of cultivar mean on environmental index.

"Coefficient of determination for cultivar mean regressed on environmental index.

Double regression method as described by Verma et al. (1978).

"Yield measured in $\mathrm{g} / 3 \mathrm{~m}$ of row.

'Critical value for significance at $P<0.05$ is 0.63 ; for VAR the critical value is 0.81 . 
sign 'Honeoye' to the bottom and 'Redcoat' to the top (Table 3).

Some of these differences occur because of the different definitions and concepts of stability. Others occur because various types of genotype-environment interactions exist; the different stability indices are each sensitive to specific types of interactions. Allard and Bradshaw (1964) discuss the complexity of such interactions, and point out that for 10 genotypes in 10 environments, there exist $10^{145}$ possible types of interactions. It is not surprising then that different methods produce different assessments of stability. Becker and Leon (1988) review the mathematical relationships among various stability indices, and discuss the statistical basis for similarities and differences.

We recalculated the stability estimates using an expanded data set that included 'Stoplight', 'Badgerbelle', 'Canoga', and 'Sparkle' from 1983 through 1986 (Table 3). The objective was to learn how much stability estimates change when the cultivar mix differs.

Similar estimates of stability and cultivar rankings occurred with the expanded data set (Table 3). Stability estimates using cv did not change because the $\mathrm{cv}$ does not consider the performance of other cultivars. VAR was not calculated for the expanded data set because of the large number (180) of separate analyses that would have been required. The $B$ index provided nearly identical rankings, although the status of 'Kent' improved with the larger data set. Consistently, 'Kent' was the exceptional cultivar because its ranking changed in the larger data set with all stability estimates.

The differences between method $\beta$ and II $\beta$ can be illustrated graphically (Fig. 2). 'Stoplight' was relatively insensitive to changes in environment when conditions were poorer than average, but responded better than average to favorable conditions. A conventional regression approach (B) gives 'Stoplight' a low ranking for stability, but its performance would be desirable to a grower.

We were interested in learning whether stability across locations was similar to stability across years. If stability estimates across locations are similar to estimates across years (as one might expect if stability were genetically determined), a tester could then hasten the evaluation of a cultivar by using many locations as opposed to fewer locations across several years.

There was not a good correlation between stability estimated across years and estimated across locations (Table 5; $r=0.44$, $N S$ ) using the regression method (ß). In fact, a few, negative regression coefficients existed, indicating that an individual cultivar performed worse as conditions generally improved. The reason for this seemingly incongruous trend is that an outlier at either environmental extreme can have asignificant impact on the regression coefficient. Barah et al. (1981 ) examined stability measured across years and locations in sorghum. They concluded that a fairly good associa- tion can exist between stability measured across years and across locations within years, but only if yield differences are large and outliers are few.

Our data also demonstrate that stability estimates made across locations can change markedly from year to year (Table 6). Leon and Becker (1988) examined the repeatability of six stability indices over 8 years. They concluded that repeatability from year to year was especially low, and that single-year results cannot serve as a basis to quantify repeatability, even if more than 10 locations are involved. Pham and Kang (1988) used a substantially larger data set to compare the correlation and repeatability of several stability indices in five separate trials of maize. They found little consistent correlation among different stability indices, a low correlation between stability index and mean yield, negligible repeatability when environments were grouped into good and poor environments, and low repeatability from indices obtained from subsets of data chosen at random.

\section{'Advantages and disadvantages of some conventional indices}

A coefficient of variation may give a quick assessment of stability when comparisons are made within a single study, but the index does not separate the effects of environment from genotype $x$ environment interaction It provides a static measure of stability that is of little value for assessing phenotypically plastic traits. Drawing conclusions about the genetic basis of yield stability from cvs is difficult, and comparisons of values from different studies are nearly meaningless.

The ANOVA technique of Homer and Frey (1957) has not been used extensively because the number of analyses becomes prohibitive when the number of cultivars is large. In addition, the stability indices are relative, so comparisons among different crops or studies become confusing. The ecovalence stability index (Wricke, 1962) might be more useful if one prefers an ANOVA approach.

One can use the ANOVA to partition out the heterogeneity of regression component from genotype $\times$ environment interaction (Fripp and Caten, 1971). The objective of

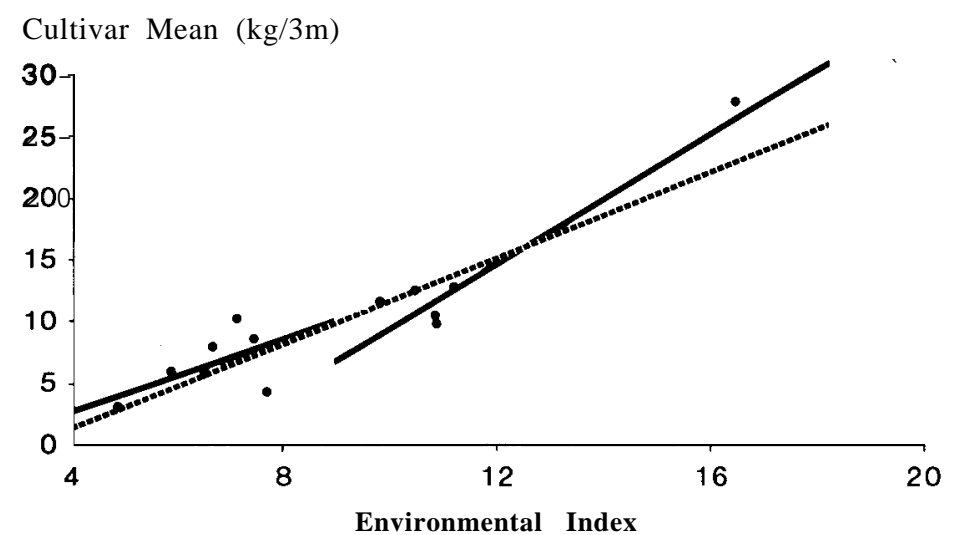

Fig. 2. Performance of 'Stoplight' strawberry regressed against an environmental index of cultivar mean yield $(\mathrm{kg} / 3 \mathrm{~m})$. Dashed line represents an assessment with a single regression line (Yield = $1.33 \mathrm{X}-15.36, R^{2}=0.81$ ). Solid line represents an assessment using two regression lines (Yield $=0.709 \mathrm{X}+3.60, R^{2}=0.15 ;$ Yield $\left.=2.69 \mathrm{X}-29.9 ; R^{2}=0.93\right)$.
Table 5. Comparison of stability estimates $(()$ across years, across locations, and across location-year combinations for various straw-

\begin{tabular}{lrcc}
\hline \hline & \multicolumn{3}{c}{ Regression coefficients $(\beta)$} \\
\cline { 2 - 4 } Cultivar & Years & Locations & Overall \\
\hline Sparkle & -0.651 & 0.267 & 0.652 \\
Kent & 1.026 & 0.731 & 0.677 \\
Redcoat & 0.524 & 1.750 & 0.720 \\
Crimson King & 0.717 & 1.069 & 0.770 \\
Canoga & -0.417 & 0.683 & 0.861 \\
Bounty & 0.973 & 0.309 & 0.940 \\
Veestar & 1.256 & 1.337 & 0.991 \\
Honeoye & 0.905 & 1.791 & 1.034 \\
Badgerbelle & 0.569 & 0.453 & 1.043 \\
Stoplight & 1.129 & 1.327 & 1.822 \\
\hline
\end{tabular}

Table 6. Stability estimates $(\beta)$ across locations for four strawberry cultivars in each of 4 years.

\begin{tabular}{ccccr}
\hline & \multicolumn{4}{c}{ Cultivar } \\
\cline { 2 - 5 } Year & Honeoye & Stoplight & \multicolumn{1}{c}{ Kent } & Redcoat \\
\hline 1983 & 0.973 & 0.982 & 1.259 & -0.552 \\
1984 & 0.789 & 2.246 & 0.352 & 0.825 \\
1985 & 1.487 & 0.770 & 1.404 & 1.475 \\
1986 & 1.162 & 1.088 & -0.498 & 2.141 \\
\hline
\end{tabular}

this joint regression analysis is to determine if the regression coefficients for the various genotypes can be expected to differ significantly. If the heterogeneity of regression component is significant, one should proceed to examine regression coefficients for individual genotypes. This joint regression analysis does not provide stability estimates for individual cultivars. The genotype $\times$ environment sums of squares can be partitioned into parts attributable to individual genotypes, but this exercise is of questionable validity because of too few degrees of freedom (Freeman and Perkins, 1971; Fripp and Caten, 1971). The other ANOVA techniques (e.g., stability variance, ecovalence) have not been widely used.

Stability indices based on a regression approach also have disadvantages, one of which is poor repeatability when yield differences are small (Leon and Becker, 1988; Pham and Kang, 1988). Other disadvantages relate to the assumptions underlying the analysis. First, to interpret regression coefficients as stabilberry cultivars. 
ity parameters, one must have selected a random sample of genotypes for the study. Since breeders usually work with highly selected material, one must know something about the covariance among genotypes before interpretation. When covariation among genotypes is high, the addition or removal of a single genotype from the analysis can greatly affect the magnitude of the regression coefficients (Miezan et al., 1979) This occurred in the strawberry data set with 'Kent' when the number of cultivars was expanded from six to 10 .

Second, the environmental index partially depends on the performance of the cultivar under analysis; therefore, some dependency exists with the "independent" variate. One could eliminate the cultivar under study from the calculation of the overall mean, or use "control" genotypes to measure environmental quality, but this would require more plots or the calculation of a separate environmental index for each regression.

Third, the regression coefficients themselves are biased because one assumption of regression analysis is lack of error in the independent variable. In stability analysis, the independent variable (environmental index) has an associated error. The degree of bias depends on the ratio of environmental variance to error variance, and on the number of genotypes in the study (Becker and Leon, 1988). For this reason, standard parametric statistical procedures for comparing stability indices are not appropriate.

Fourth, there is some debate if deviation from regression is an appropriate measure of cultivar stability because it lacks any predictive value and is not likely to be determined genetically (Lin et al., 1986). Hardwick and Wood (1972) point out that deviations from regression are not independent of the regression coefficients themselves; therefore, the two stability criteria of Eberhart and Russell (1966) are not truly independent measures. Lin and Binns (1988) address this problem by dividing the genotype $\times$ environmental interaction into a predictable and unpredictable component. The predictable component is derived from regression on the environmental index, while the unpredictable component is an average of within-location variance across years. This approach is useful when one suspects that large nonlinear relationships exist in the data.

Fifth, poor environments in field studies may not be considered poor by growers' standards. One may arbitrarily classify half the environments in a study as poor, but, when a cultivar is planted throughout a region, performance may be different than predicted because the regional average is different from the average in the study. It is difficult to ensure that the trial environments adequately represent the target population of environments.

Sixth, stability indices are not absolute measures of performance-they provide a ranking relative only to those genotypes in the study. Furthermore, the rankings are appropriate only for the examined set of environments and cultural systems. If one were to include results from additional extreme environments or cultural systems in the data set, the performance index would be affected in two ways: a) the environmental mean would change, resulting in different regression coefficients; and b) the sum of squares for the environmental index would increase, which would reduce the standard error of the regression coefficients if extreme values fell along regression lines. Of course, when one includes more extreme environments, the possibility of encountering nonlinear interactions increases. A conventional regression approach is satisfactory only when many genotypes, environments, and replications are used; when a large portion of the genotypeenvironment interaction is linear (few outliers); when the error variances of genotypes are homogeneous (Skroppa, 1984); or when modifications of the analysis are made (Verma et al., 1978). If a curvilinear response does exist, one must decide at what point in the environmental range does the change from linearity to curvilinearity occur (Snoad and Arthur, 1976).

The stability index of Verma et al. (1978) is very practical when assessing stability over a wide range of environments. This analysis, however, requires more environments or replications to obtain the same level of confidence in regression lines because two, rather than one, must be estimated. This index is useful when nonlinear responses to environment occur. One could also classify the environments as poor or good based on prior experience or knowledge, rather than dividing the environments equally between the two groups.

\section{ALTERNATIVE INDICES}

Several modifications of the generalized (joint) regression approach have been developed and used to assess genotype stability (Perkins and Jinks, 1968; Digby, 1979; Freeman, 1973; Hardwick and Wood, 1972). These have not been used widely by plant scientists. Nonparametric methods have also been used because the stability measures are distribution-free and not as affected by outliers (Nassar and Huhn, 1987).

\section{Multivariate approaches}

Other measures of stability have been proposed that involve multivariate approaches (Freeman and Dowker, 1973; Grafius and Kiesling, 1960; Gower, 1966; Kempton, 1984; Ghaderi et al., 1982; Wescott, 1986; Lin et al., 1986). In general, environments are treated as variables and genotypes as replications, and genotypes are assigned to different homogeneous stability subsets. Such approaches have yet to be widely adopted by plant scientists because of the complexity of analysis, the difficulty in interpreting classifications, and their inability to provide a simple measure of stability.

\section{CONCLUSIONS}

Although there are many potential uses for stability indices in horticultural science, one must be aware of their assumptions and lim- itations. The first step in choosing an index is to decide which concept of stability is appropriate. A cv may not be appropriate for many quantitative traits. A second step is to decide between the available stability indices. The widely used index of Findlay and Wilkinson (1963) may not be the most desirable because it penalizes genotypes with a better-than-average response under good conditions.

Modifications and alternatives to conventional regression approaches have been presented in the literature; those protecting against violations of assumptions are usually computationally complex. Although it is important to use a statistically valid technique for assessing stability, it is also important that the technique be relatively easy to use for those not trained in statistical theory (Hill, 1975).

When using any stability index, one must be aware of the following: 1) outliers can have a significant impact on the stability estimates, 2) other cultivars in the data set can have a marked effect on stability indices, 3 ) indices are often inconsistent from year to year, 4) indices often lose their predictive value outside the range of environments where the assessment was made, 5) stability of yield is not necessarily related to stability of yield components (Bains and Gupta, 1972; Singh and Bains, 1984), and 6) studies have shown that the heritability of stability is quite low, especially stability measured by deviations from regression (Becker and Leon, 1988).

\section{Literature Cited}

Allard, R.W. and A.D. Bradshaw. 1964. Implications of genotype-environmental interactions in applied plant breeding. Crop Sci. 4:503-508.

Ariyo, O.J. 1987. Stability of performance of okra as influenced by planting date. Theor. Applied Genet. 74:83-86.

Bains, K.S. and V.P. Gupta. 1972. Stability of yield and yield components in bread wheat. Ind. J. Gen. Plant Breed. 32:306-312.

Barah, B. C., H.P. Binswanger, B.S. Rana, and N.G.P. Rae. 1981. The use of risk aversion in plant breeding: Concept and application. Euphytica 30:835-840.

Becker, H.C. and J. Leon. 1988. Stability analysis in plant breeding. Plant Breed. 101: 1-23.

Berry, S.Z., M.R. Uddin, W.A. Gould, A.D. Bisges, and G.D. Dyer. 1988. Stability in fruit yield, soluble solids, and citric acid of eight machine-harvested processing tomato cultivars in northern Ohio. J. Amer. Soc. Hort. Sci. 113:604-608.

Breese, E.L. 1969. The measurement and significance of genotype-environment interactions in grasses. Heredity 24:27-44.

Brennan, P.S. and D.E. Byth. 1979. Genotype $\times$ environmental interactions for wheat yield and selection for widely adapted wheat genotypes. Austral. J. Agr. Res. 30:221-232.

Carver, B. F., E.L. Smith, and H.O. England. 1987. Regression and cluster analysis of environmental responses of hybrid and pureline winter wheat cultivars. Crop Sci. 27:659-664.

Digby, P.G.N. 1979. Modified joint regression analysis for incomplete variety $x$ environment data. J. Agr. Sci. 93:81-86

Dowker, B. D., J.C. Jackson, and K. Phelps. 1978. Variation studies in carrots as an aid to breeding: VI. Genotype-environment interactions in 
contrasting field environments. J. Hort. Sci. 53:131-137.

Eberhart, S.A. and W.A. Russell. 1966. Stability parameters for comparing varieties. Crop Sci. 6:36-40.

Fennell, J.F.M. and P.J. Salter. 1977. Genotypic and environmental variation in autumn sown onions. Theor. Applied Genet. 51:21-28.

Findlay, K.W. and G.N. Wilkinson. 1963. The analysis of adaptation in a plant breeding programme. Austral J. Agr. Res. 14:742-754.

Francis, T.R. and L.W. Kannenberg. 1978. Yield stability studies in short-season maize: 1 . A descriptive method for grouping genotypes. Can J. Plant Sci. 58:1029-1034.

Freeman, G.H. 1973. Statistical methods for the analysis of genotypc-environment interactions. Heredity 31:339-354.

Freeman, G.H. and B.D. Dowker. 1973. The analysis of variation between and within genotypes and environments. Heredity 30:97-109.

Freeman, G.H. and J.M. Perkins. 1971. Environmental and genotype-environmental components of variability: VIII. Relations between genotypes grown in different environments and measures of these environments. Heredity 26:1523.

Fripp, Y.J. and C.E. Caten. 1971. Genotype-environment interactions in Schizophyllum commune: I. Analysis and character. Heredity 27:393-407.

Ghaderi, A., M.W. Adams, and A.W. Saettler. 1982. Environmental response patterns in commercial classes of common bean (Phascolus vulgaris L.). Theor. Applied Genet. 63: 17-22.

Gower, J.C. 1966. Some distance properties of latent root and vector methods used in multivariate analysis. Biometrics 53:325-338.

Grafius, J.E. and R.L. Kiesling. 1960. The prediction of relative yields of different oat varieties based on known environmental variables. Agron. J. 52:396-399.

Gray, E. 1982. Genotype $\times$ environmental interactions and stability analysis for forage yield of orchard grass clones. Crop. Sci. 22:19-23.

Hancock, J.F. 1985. Yield stability in 10 cultivars of strawberry. Fruit Var. J. 39:18-21.

Hanson, W.D. 1970. Gcnotypic stability. Theor. Applied Genet. 40:226-231.

Hardwick, R.C. and J.T. Wood. 1972. Regression methods for studying genotype-environment interactions. Heredity 28:209-222.

Heinrich, G. M., C.A. Francis, and J.D. Eastin. 1983. Stability of grain sorghum yield components across diverse environments. Crop Sci. 23:209-212.
Hill, J. 1975. Genotype-environment interaction-a challenge for plant breeding. J. Agr. Sci. 85:477-493.

Homer, T.W. and K.J. Frey. 1957. Methods for determining natural areas for oat varietal recommendations. Agron. J. 49:313-315.

Kanua, M.B. and C.N. Floyd. 1988. Sweet potato genotype $\times$ environment interactions in the highlands of Papua New Guinea. Trop. Agr. $65: 9-15$.

Kempton, R.A. 1984. The use of biplots in interpreting variety by environment interactions. J. Agr. Sci. 103:123-135.

Leon, J. and H.C. Becker. 1988. Repeatability of some statistical measures of phenotype stability-correlations between single year results and multiyear results. Plant Breed. 100: 137-142.

Lin, C.S. and M.R. Binns. 1988. A method of analyzing cultivar $\times$ location $\times$ year experiments: A new stability parameter. Theor. Applied Genet. 76:425-430.

Lin, C. S., M.R. Binns, and L.P. Lefkovitch. 1986. Stability analysis: Where do we stand? Crop Sci. 26:894-900.

Luby, J. J., E.E. Hoover, S.T. Munson, D.S Bedford, D.K. Wildung, and W.H. Gray. 1984. Performance of strawberry cultivars in Minnesota: 1983. Adv. Strawberry Prod. 3:11-14.

Miezan, K., G.A. Milliken, and G.H. Liang. 1979. Using regression coefficient as a stability parameter in plant breeding programs. Theor. Applied Genet. 54:7-9.

Nassar, R. and M. Huhn. 1987. Studies on estimation of phenotypic stability: Test of significance for nonparametric measures of phenotypic stability. Biometrics 43:45-53.

Ng, T.J, C.A. McClurg, F.F. Angell, and J. I.Anderson. 1980. Evaluation of muskmelon cultivar performance by joint regression analysis. J. Amer. Soc. Hort. Sci. 105:220-223.

Ntare, B.R. and M. Aken'Ova. 1985. Yield stability in segregating populations of cowpea. Crop Sci. 25:208-211.

Olson, S.M. and P.J. Stoffella. 1989. Yield stability differences among collard cultivars. HortScience 24:495-497.

Perkins, J.M. and J.L. Jinks. 1968. Environmental and genotype-environmental components of variability: III. Multiple lines and crosses. Heredity 23:339-356.

Pham, H.N. and M.S. Kang. 1988. Interrelationships among and repeatability of several stability statistics estimated from international maize trials. Crop Sci. 28:925-928.

Pinthus, M.J. 1973. Estimate of genotypic value: A proposed method. Euphytica 22:121-123.
Plaisted, R.L. and L.C Peterson. 1959. A technique for evaluating the ability of selections to yield consistently in different locations and seasons. Amer. Potato J. 36:381-385.

Poysa, V. W., R. Garton, W.H. Courtney, J.G. Metcalf, and J. Muehmer. 1986. Genotype-environment interactions in processing tomatoes in Ontario. J. Amer. Soc. Hort. Sci. 111:293297.

Saeed, M. and C.A. Francis. 1983. Yield stability in relation to maturity in grain sorghum. Crop Sci. 23:683-687.

Salmon, S.C. 1951. Analysis of variance and longterm variety tests of wheat. Agron. J. 43:562570.

Shukla, G.K. 1972. Some statistical aspects of partitioning genotype-environmental components of variability. Heredity 29:237-245.

Siefker, J.H. and J.F. Hancock. 1986. Stability of yield in highbush blueberry cultivars. Fruit Var. J. 40:5-7.

Singh, H. and K.S. Bains. 1984. Stability analysis of varietal mixtures in chickpea (Cicer arietinum L.). Z. Pflanzenzüchtg. 92:159-167.

Skroppa, T. 1984. A critical evaluation of methods available to estimate the genotype $\times$ environment interaction. Studia Forestalia Suecica 166:3-14.

Snoad, B. and A.E. Arthur. 1976. The use of regression techniques for predicting the response of peas to environment. Theor. Applied Genet. 47:9-19.

Stoffella, P.J., H.H. Bryan, T.K. Howe, J.W. Scott, S.L. Locascio, and S.M. Olson. 1984. Stability differences among fresh market tomato genotypes: L Fruit yields. J. Amer. Soc. Hort. Sci. 109:615-618.

Tan, W., G. Tan, and P.D. Walton. 1979. Regression analysis of genotype-environment interaction in smooth bromegrass. Crop Sci. 19:393-396.

Verma, M. M., C.S. Chahal, and B.R. Murty. 1978. Limitations of conventional regression analysis: A proposed modification. Theor. Applied Genet. 53:89-91.

Wescott, B. 1986. Some methods of analysing genotype-environment interactions. Heredity 56:243-253.

Williams, H. 1975. Genotype-environment interaction in strawberry cultivars. Hort. Res. 14:8188.

Wricke, G. 1962. Über eine Methode zur Erfassung der ökologischen Streubreite in Feldversuchen. Z. Pflanzenzüchtg. 47:92-96. 